\title{
Combining capacitor/inductor and idling asynchronous motor in design of a system for balance of a large two-phase industrial load over three phases
}

\author{
Eugene Coyle \\ Technological University Dublin, Eugene.Coyle@tudublin.ie \\ M Farrell \\ Technological University Dublin \\ W. J. Campbell \\ Technological University Dublin
}

Follow this and additional works at: https://arrow.tudublin.ie/engscheleart

Part of the Electrical and Computer Engineering Commons

\section{Recommended Citation}

Coyle, Eugene and Farrell,M. and Campbell, W. J. :Combining capacitor/inductor and idling asynchronous motor in design of a system for balance of a large two-phase industrial load over three phases. PEMD 2004:second International Conference on power electronics, machines and drives, 31 March - 2 April, 2004, pp.600-604. doi:10.21427/5kpz-b037

This Conference Paper is brought to you for free and open access by the School of Electrical and Electronic Engineering at ARROW@TU Dublin. It has been accepted for inclusion in Conference papers by an authorized administrator of ARROW@TU Dublin. For more information, please contact arrow.admin@tudublin.ie, aisling.coyne@tudublin.ie,gerard.connolly@tudublin.ie.

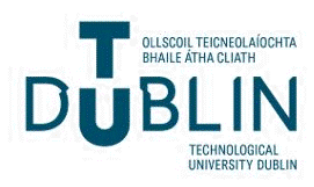


School of Electronic and Communications Engineering

Conference papers

Dublin Institute of Technology

Year 2004

\title{
Combining capacitor/inductor and idling asynchronous motor in design of a system for balance of a large two-phase industrial load over three phases
}

\author{
Eugene Coyle* $\quad$ H. O'Farrell ${ }^{\dagger}$
}

W. J. Campbell ${ }^{\ddagger}$

*Dublin Institute of Technology, Eugene.Coyle@dit.ie

${ }^{\dagger}$ Dublin Institute of Technology

¥Dublin Institute of Technology

This paper is posted at ARROW@DIT.

http://arrow.dit.ie/engschececon/52 


\section{— Use Licence}

\section{Attribution-NonCommercial-ShareAlike 1.0}

You are free:

- to copy, distribute, display, and perform the work

- to make derivative works

Under the following conditions:

- Attribution.

You must give the original author credit.

- Non-Commercial.

You may not use this work for commercial purposes.

- Share Alike.

If you alter, transform, or build upon this work, you may distribute the resulting work only under a license identical to this one.

For any reuse or distribution, you must make clear to others the license terms of this work. Any of these conditions can be waived if you get permission from the author.

Your fair use and other rights are in no way affected by the above.

This work is licensed under the Creative Commons Attribution-NonCommercialShareAlike License. To view a copy of this license, visit:

- URL (human-readable summary):

http://creativecommons.org/licenses/by-nc-sa/1.0/

- URL (legal code):

http://creativecommons.org/worldwide/uk/translated-license 


\title{
COMBINING CAPACITOR/INDUCTOR AND IDLING ASYNCHRONOUS MOTOR IN DESIGN OF A SYSTEM FOR BALANCE OF A LARGE TWO-PHASE INDUSTRIAL LOAD OVER THREE PHASES.
}

\author{
Coyle E., O'Kelly H., Farrell M., Campbell W.J. \\ Dublin Institute of Technology, Kevin Street, Dublin 8, Ireland. \\ eugene.coyle@dit.ie \\ Fax: 00-353-1-4024996
}

Keywords: Phase-Balance, Harmonic Distortion, Idling Motor, Unbalance

\begin{abstract}
This paper describes the design and implementation of a new solution to power quality problems associated with large unbalanced non-linear loads at fine glass furnace production utilities. Such furnaces use two-phase electricity for reasons of enhanced temperature control and in order to maintain consistency of glass viscosity. A significant risk of power failure is introduced due to this requirement. The furnace load is also non-linear in nature, due to temperature control by electronic power switching. This gives rise to risks associated with high harmonic distortion. A new method in design of filters to alleviate problems associated with this type of load is also described.
\end{abstract}

\section{Introduction}

Over the past decade the manufacture of fine glass products by such companies as Waterford Crystal of Ireland, Stuart Crystal of UK, Swarovski of Austria, Atlantis of Portugal, has become automated, with skills transferred from craft workers to robotic production systems. The process also involves the replacement of the traditional pot furnaces used by the glass blowers, with large industrial electrically heated units having power ratings in the region of $1 \mathrm{MW}$ to $3 \mathrm{MW}$.

These furnaces are constructed using a glass-based refractory brick and the glass is generally kept in a molten state at 1,150 degrees Centigrade by means of resistance heating. To achieve this, a large current is passed through the molten glass. If power to the furnace fails, the contents begin to cool down immediately. As the temperature reduces the glass resistance increases, reducing its ability to absorb power. A point is quickly reached (quarter to half an hour depending on furnace size) where the molten glass fuses with the refractory brick. Once this happens the process becomes irreversible and the whole furnace turns into a solid glass block. The only solution at this point is to break up and remove the glass block and rebuild the entire furnace. Such a failure would result in major rebuild costs together with consequent loss of production and market. The rebuild cost alone, of a typical 1 Mega-Watt furnace is estimated to be in the region of 12 million Euro.

In order to reduce the risk of such a failure, electric glass furnace manufacturers and users have examined and treated weaknesses in the construction and within the electrical supply configuration. One of the major remaining weaknesses is the fact that these furnaces used two-phase electricity for reasons of enhanced current direction control and consistency of glass viscosity. This configuration, if not corrected for, will result in significant unbalance of phase currents and voltages within the plant and on the feeding three-phase utility supply. Two-phase configurations can introduce significant risks of power failure, due to maloperation of critical auxiliary equipment and the furnace itself. The furnace load is also non-linear in nature, due to temperature control by thyristor switching. This gives rise to risks associated with high harmonic distortion, which can result in failure of essential ancillary equipment and indeed of the supply system itself.

\section{Converting Three-Phase to Two-Phase}

There are a number of well known methods of distributing a two-phase load across three phases. These include Scott wound transformer, Capacitor/Inductor method, Le Blanc transformer, PWM converter, motor generator.

The two most commonly used in the glass industry are Scott wound transformers and capacitor-inductor combinations.

\subsection{Scott Transformer Method}

Scott wound transformers consist generally of two independent two-phase transformers. A centre tap from the primary of the first (main) transformer is brought out and connected to one pole of the primary of the second (called the teaser transformer). The secondaries of these transformers will produce two voltages in quadrature, which can be arranged to be of equal magnitude. Although originally used - to supply two-phase motors form a three-phase supply; they can also be arranged to distribute a two-phase load over three phases. This is achieved by leaving the secondary of the main transformer open, and connecting the two-phase load across 
the secondary of the teaser transformer. The result is that the load current is split in the ratio 2:1:1 across the three-phase supply.

A disadvantage of the Scott method is that additional load must be added across two phases to achieve and maintain balance. Further difficulties will arise if the power factors of the Scott transformer and of the added load differ.

\subsection{Capacitor/Inductor Method}

A two-phase resistive load may be converted to three-phase balanced by the connection of an inductor and capacitor between the loaded phases and the unloaded one. Circuit and Phasor diagrams are shown in figures 1 and 2.

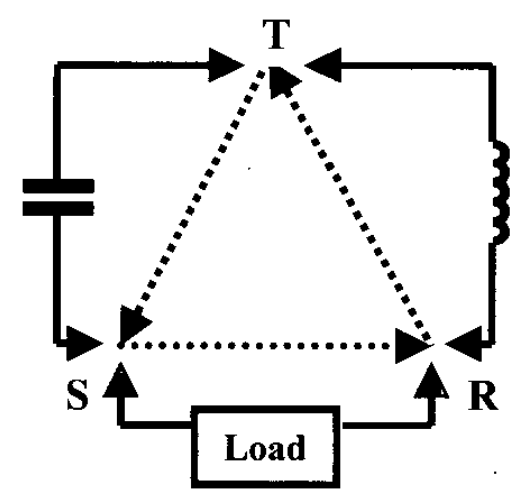

Figure 1 Capacitor-Inductor balancer

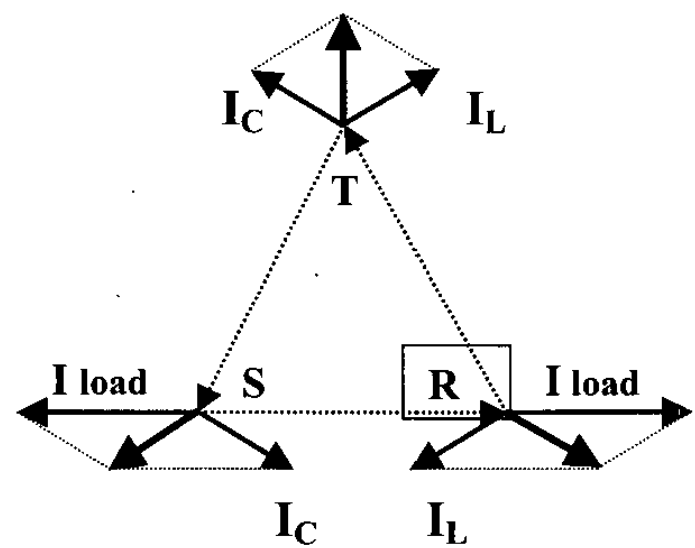

Figure 2 Phasor diagram of C-L balancer

$\mathbf{I}_{\mathbf{C}}$ and $\mathbf{I}_{\mathbf{L}}$ represent the capacitor and inductor currents represents the resistive load current flowing in $\mathrm{R}$ and $\mathrm{S}$ phases. Appropriate selection of inductor and capacitor values leads to a balanced set of resultant current vectors (shown in black).

To achieve this both $\mathbf{I}_{\mathbf{L}}$ and $\mathbf{I}_{\mathbf{C}}$ must have the value

$$
\frac{P}{2 V \cos 30} \text { amps }
$$

where $\mathrm{P}$ represents the full load power and V the supply system voltage.

Both $\mathrm{L}$ and $\mathrm{C}$ will in this case have equal reactance at $50 \mathrm{~Hz}$. An important point of note is that $\mathrm{L}$ and $\mathrm{C}$ will form a $50 \mathrm{~Hz}$ series tuned circuit across $\mathrm{R}$ and $\mathrm{S}$, if $\mathrm{T}$ phase is disconnected. Should the T phase become disconnected, this tuned circuit would produce a short circuit between the $\mathrm{R}$ and $\mathrm{S}$ phases. In practice this situation can arise from fuse failure or loss of phase from the supply source. It can also occur momentarily during the closing or opening of a feeding contactor or circuit-breaker. The latter situation arises due to mechanical time differences in the closing or opening of the individual phase contacts.

\section{Capacitor Inductor Model}

The main difficulty with past attempts to use Capacitor / Inductor method has been this problem relating to the danger of $50 \mathrm{~Hz}$ resonance in the event of the centre phase ( $\mathrm{T}$ phase in this case) becoming disconnected. Figure 6 shows how this leads to the occurrence of a short circuit between $\mathrm{R}$ and $\mathrm{S}$ phases.

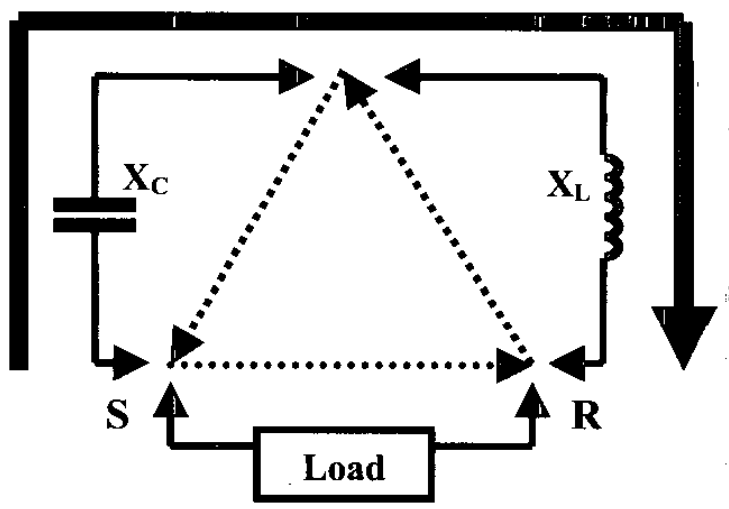

Figure 6 Fifty $\mathrm{Hz}$ resonant circuit

A laboratory experiment was set up to measure over-current and over-voltage in the event of centre phase loss with a capacitor/inductor balancer. 
The experiment involved the use of commercially available capacitors and inductors of the type proposed for the balancer. The capacitors were connected in series-parallel configurations to allow for high voltage during the test. The objective was to measure the peak and RMS capacitor voltage after disconnection of the $T$ phase. From the measurements it was concluded that a peak voltage of $2.2 \mathrm{kV}$ and an RMS of $1.053 \mathrm{kV}$ would be reached.

It was concluded that the removal of the central phase would result in the capacitor being over-stressed, with the consequent possibility of violent failure. It was therefore deemed necessary to take account of this fact in the design of any balancer built using capacitor / inductor combinations.

It was decided to introduce impedance between the centre phase ( $\mathrm{T}$ phase) and the other two phases in order to limit the capacitor voltage in the case of $T$ phase becoming disconnected. This was achieved by connecting idling asynchronous motors in such a way that the balancer would not function unless these were running.

Two motors were installed for this purpose. Only one was required, the other was to act as a standby.

The motors used were ABB catalogue number N2BA 132315 SMB, rated $132 \mathrm{~kW}$ at 400 volt with $95.3 \%$ efficiency, and at 0.80 power factor. For these motors, manufacturers test data indicated that

$Z_{1}=0.66+j 1.83 \mathrm{ohms}$

$\mathrm{Z}_{2}=0.031+\mathrm{j} 0.15 \mathrm{ohms}$

$\mathrm{Z1}$ and $\mathrm{Z} 2$ are the positive and negative phase sequence impedances of the motor running under no-load.

Rated current is 254 amps at 0.85 power factor

The voltage level with motor connected and $\mathrm{T}$ phase removed was then calculated. It was concluded that in the worst case situation a capacitor voltage of 887 volts could be reached. This was within the short term withstand capability of the capacitor, and would also cause the main balancer circuitbreaker to trip on over-voltage, after a short period.

\section{Balancer comprising Capacitor/Inductor with Idling Motor}

After further investigation it was concluded that the idling motor could contribute balancing currents if it was supplied from a deliberately unbalanced voltage source. The objective was to reverse the process developed by Campbell [1] who described a method by which a single-phase supply can be converted to a three-phase supply using an asynchronous motor.
The approach illustrated here is based on the addition of suitable three-phase negative sequence currents to that of a two-phase load, in order to create a set of balanced threephase currents. This solution is best described using the method of Kemp [2], for the derivation of positive and negative phase sequence components.

\section{$5 \quad$ Kemp Method}

Kemp described a graphical method of deriving the positive and negative phase sequence components of a three-phase system of voltages or currents [5]. This method, outlined here, is more suitable for explaining the operation of the balancer.

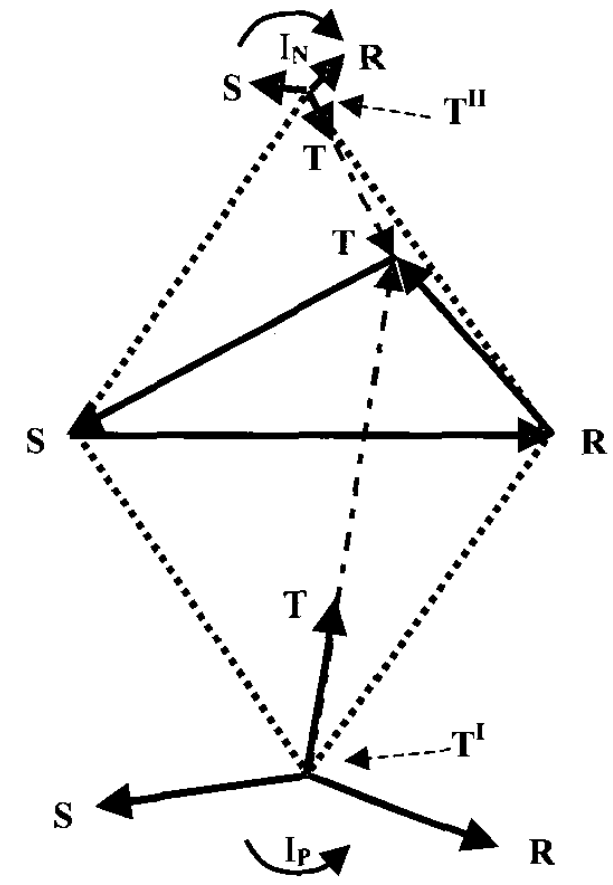

Figure 3 Kemp construction for unbalance load

Referring to Figure 3; consider a three-phase system of unbalance currents (shown in blue).

Based on the RS phase line, two equilateral triangles are drawn and the extremities marked as $\mathrm{T}^{\mathrm{I}}$ and $\mathrm{T}^{\mathrm{II}}$ (shown dotted).

Join $\mathrm{T}^{\mathrm{I}}$ and $\mathrm{T}^{\mathrm{II}}$ to $\mathrm{T}$.

Kemp proved the vector $\mathrm{T}^{\mathrm{I}} \mathrm{T} \div 3$ represents the magnitude and direction of the $T$ component of a balanced positive phase sequence set of currents (shown in red). The vector $\mathrm{T}^{\mathrm{ll}} \mathrm{T} \div$ 3 represents in magnitude and direction the $\mathrm{T}$ component of a 
balanced negative phase sequence set of currents (shown in green).

This argument holds equally well for a two-phase resistive current $I_{S}$ flowing between two phases (say $R$ and $S$ phases). This current is equivalent to a three-phase system, with $I_{R}$ flowing in $R, I_{S}\left(=-I_{R}\right)$ flowing in $S$ phase, and zero current flowing in $T$ phase. Figure 4 demonstrates, using the Kemp construction, the resolution of this two-phase current into its positive and negative phase sequence three-phase components.

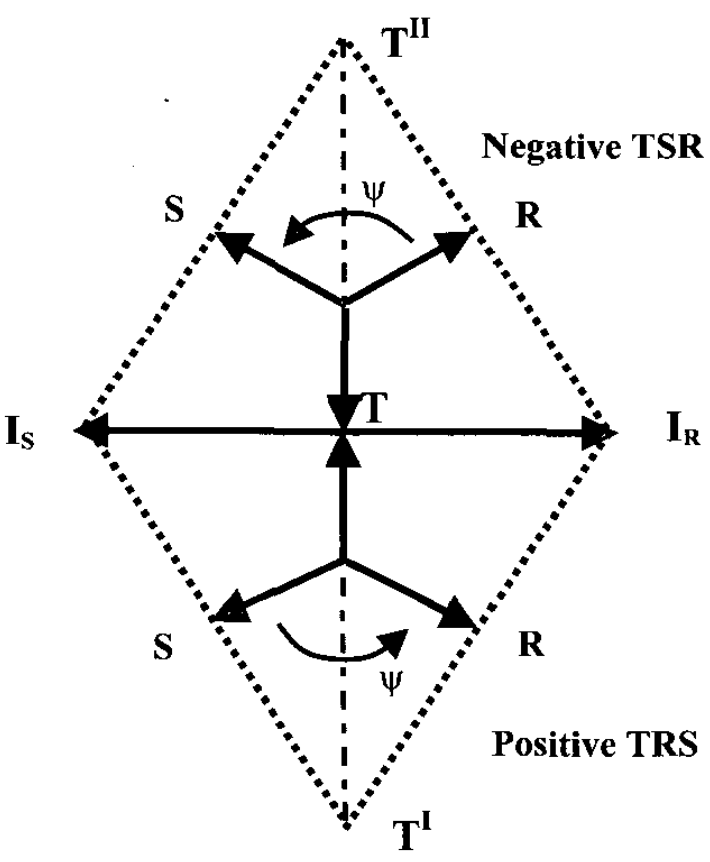

Figure 4 Kemp construction for two-phase load

$I_{S}$ and $I_{R}$ represent the full load current flowing in $R$ and $S$ phases. If a negative phase sequence current equal and opposite to $I_{N}$ is injected into the three-phase system, the resultant seen by the supply system is the balanced threephase positive phase sequence component of $I_{S}$ and $I_{R}$.

Since $\quad I=I_{1}+I_{2}$

It follows that $I_{1}=I-I_{2}$

From this we can deduce that if a current equal and opposite to the negative phase sequence component, is added to the unbalanced system, the resultant will be a set of balanced positive phase sequence currents.

\section{Prototype Design}

A prototype unit was built to balance a test furnace. This was installed on a trial furnace located at the Waterford Crystal factory in Butlerstown, Dungarvan. This furnace had a twophase heating load of $30 \mathrm{~kW}$, connected across two phases of a 400-volt three-phase supply. The unit comprised two 7.5 $\mathrm{kW}$ pilot-motors (arranged to rotate in opposite directions on a common mounting frame) and five capacitor/inductor steps (5 kVAr capacitors and $203 \mathrm{mH}, 64 \mathrm{ohm}$ inductors). Utilising two motors enabled a reduction of noise and vibration, by cancellation.

The motors were supplied with and unbalanced voltage by using auto-transformers connected as shown in figure 5 .

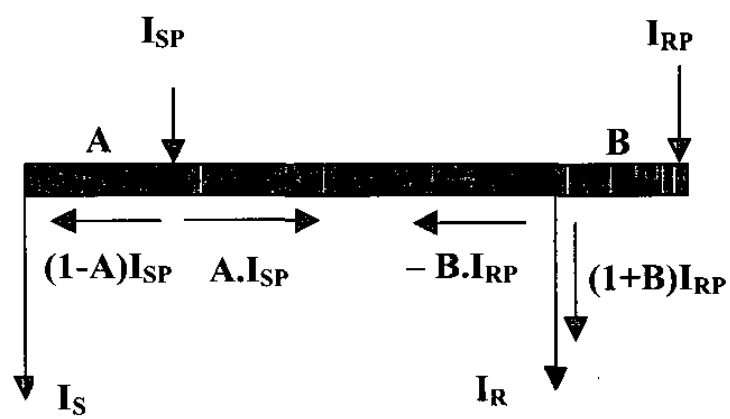

Figure 5 Current flow in the auto-transformer

For the prototype unit, design calculations realised optimum value of A-tap and B-tap transformer values of $0.2125 \mathrm{~V}$ and $0.0975 \mathrm{~V}$ respectively, maximum pilot current $9.98 \mathrm{~A}$, maximum capacitor voltage with T-phase removed $488 \mathrm{~V}$.

The balancer was wired so that the $T$ phase connection was always maintained between the capacitor steps and the pilot motors, once the balance was switched on. This was to ensure that appropriate impedance always remained in place across the capacitors, so limiting voltage rise.

The capacitor / inductor steps were controlled to follow the load profile thus maintain optimum balance.

\section{Production Model}

Following the successful operation of the test balancer, a fullscale model of the phase balancer was subsequently constructed and installed at the Waterford Crystal plant, Kilbarry, Waterford City. The furnace consists of two main sections; firstly the tank where the solid glass fillings are heated to a molten state; secondly a long section of molten 
glass channels called the Foreheart. From the latter section glass blowers, and robotic production machinery, extract molten glass for moulding into finished product. The high. level of load unbalance was causing reliability problems for production and auxiliary motive power equipment connected to the furnace.

The control circuitry of the balancer was set to monitor furnace two phase load current. The motor balancer was sized to maintain balance for furnace base load while the capacitor / inductor steps were to follow load variation. The latter were controlled by load current sensing relays set to the appropriate value for each step.

The control algorithm was optimised so as to ensure voltage unbalance did not exceed $1 \%$.

\section{Results}

By connecting the balancer to the furnace, the level of voltage unbalance was reduced from a negative phase sequence voltage of 2.94 percent to 0.87 percent. The latter value was largely due to system unbalance at the point of connection. By reaching a value lower than $1 \%$ the IEC conditions for full load running of motors [4] were established.

\section{Harmonic Distortion Issues}

Under European Supply Quality Standard EN50160 [5] limits are set for the maximum voltage unbalance and harmonic distortion, which may appear at the point of common coupling between a customer and an electrical utility. Electronic load control such as by thyristor, can introduce harmonic distortion and other power quality problems, which must be addressed.

Distortion measurements were carried out after the furnace was running and the voltage distortion levels were found to be above G5/4 planning levels [6]. As these levels are selected to minimise the possibility of problems for connected load; it was decided that the measured levels should be reduced by the application of suitably designed passive filters.

It was decided to design a passive filter bank to absorb the harmonic currents generated by the thyristor load. A software programme was designed enabling the input of maximum currents generated at $3^{\text {td }}, 5^{\text {th }} 7^{\text {th }}, 9^{\text {th }}, 11^{\text {th }}, 13^{\text {th }}, 17^{\text {th }}$, and $19^{\text {th }}$.

The program was written around standard commercially available capacitor power and voltage ratings.-The program allows the dimensioning of the filter bank components taking account of voltage, current, harmonic and thermal limitations.
For practical design considerations, a balanced filter layout topology was implemented. The bank designed consisted of $3^{\text {rd }}, 5^{\text {th }}, 7^{\text {th }}$ and $11^{\text {th }}$ tuned branches, each consisting of three steps and controlled by a power factor controller. Power factor control was possible because of the displacement power factor resulting from the thyristor phase angle control of the heating circuits. This power factor was shown by measurement to have a near linear relationship with harmonic current generated by the load.

\section{References}

[1] W.J. Campbell, "Improvements in and Relating to Rotary Phase Converters'. U.K. Patents no. 160 4921, Irish Patent.no. 44626, 1971.

[2] P. Kemp, 'A.C. Current Electrical Engineering', Macmillan, 1963.

[3] M. Heathcoat, 'J \& P Transformer Book $12^{\text {th }}$ edition', Newnes, 1998.

[4] IEC, Document 60034-1, 'Rotating Electrical Machines part 1: Rating and Performance, revision 3' 1969.

[5] National Standards Authority, EuroNorm standard 50160, 'Voltage Characteristics of Electricity Supplies by Public Distribution Systems', 1995.

[6] Electricity Asśociation UK, Engineering Recommendation G5/4, 'Planning Levels for Harmonic Voltage Distortion and Connection of Non-Linear Equipment to Transmission Systems and Distribution Networks', 2001. 